\title{
STUDY OF ACUTE LOWER RESPIRATORY TRACT INFECTIONS IN CHILDREN OF AGE GROUP 1 MONTH TO 5 YEARS
}

Y. Siva Rama Krishnaํ, K. Ramireddy², S. Aparna³ , G. Anusha4, S. Mounika5, K. Sandeep 6

\section{HOW TO CITE THIS ARTICLE:}

Y. Siva Rama Krishna, K. Ramireddy, S. Aparna, G. Anusha, S. Mounika, K. Sandeep. "Study of Acute Lower Respiratory Tract Infections in Children of Age Group 1 Month to 5 Years". Journal of Evolution of Medical and Dental Sciences 2015; Vol. 4, Issue 28, April 06; Page: 4868-4877, DOI:10.14260/jemds/2015/706

ABSTRACT: ALRTI are one of the commonest causes of morbidity and mortality in children in developing countries. Aim of the study was to evaluate children with severe LRTI (pneumonia) correlate it with radiological findings and bacteriological examination, to identify the risk factors and to study the efficacy of various antibiotics that were used routinely in our sector. This was a prospective clinical study of severe LRTI(pneumonia) conducted on 200 children who were admitted to Pediatric ward from Oct 2010 to Sept 2012 at Govt. General Hospital, Guntur, AP. Children from 1month to 60 months included in the study. Detailed history and clinical examination findings were documented. Routine investigations like CBP, ESR and CXR were done for all cases and blood cultures were done in relevant cases. All patients received antibiotics and supportive care. We found most common age group from 1 month to 1year, males were more affected than females with ratio 1:1.9. Almost all patients presented with symptoms and signs like hurried breathing, cough, fever, chest retractions, crepitations. Symptoms and signs mentioned by WHO, ARI control programme were very sensitive and can be applied to Hospitalized children. Most common type of sever LRTI was Bronchopneumonia (83\%). Most common risk factor was PEM of various grades (52\%) and anemia, incomplete immunization being other risk factors. Blood culture was positive only $7.8 \%$ of cases. Majority (83\%) responded to first line antibiotic like crystalline penicillin and amikacin.

KEYWORDS: Pneumonia, LRTI, Tachypnea, septicemia, PEM.

INTRODUCTION: Acute respiratory infections (ARI) are one of the commonest causes of morbidity and mortality in children in developing countries. It is responsible for an estimated 4 million deaths worldwide. Almost all ARI deaths in young children are due to acute lower respiratory tract infections (ALRTI), mostly pneumonia. ${ }^{1}$ Industrialization and urbanization are now posed with the problem of increase in ARI morbidity and mortality. It is clear that future health of children depends on preventing, diagnosis, treating and or limiting ALRTI.

The utility of simple clinical signs like rapid breathing and chest in drawing to diagnose pneumonia in infants and young children has been well established. The use of these clinical signs in the early detection and treatment of children with pneumonia by primary health care workers forms the basis for the case management strategy formulated by the World Health Organization (WHO) to control mortality and morbidity. ${ }^{2}$

Empirical antibiotic therapy for pneumonia is the commonly accepted practice world wide as the etiology of pneumonia in children is difficult to establish. Clinical and radiological criteria do not accurately reflect the etiology of childhood pneumonia. ${ }^{3}$

The present study is designed to clinically evaluate children with pneumonia, correlate it with radiological findings, to identify the risk factors and to study the efficacy of various antibiotics that are used routinely in our sector. 


\section{ORIGINAL ARTICLE}

\section{AIMS AND OBJECTIVES:}

1. To study the clinical, radiological and epidemiological features of severe pneumonia in children in age group of 1 month to 5years of age.

2. To correlate clinical findings with radiological and bacteriological examination.

3. To know the choice of antibiotic for severe pneumonia.

MATERIALS AND METHODS: This was a prospective clinical study of severe pneumonia conducted on 200 children who were admitted to pediatric wards from October 2010 to September 2012 at Govt. General Hospital, Guntur. The epidemiological factors affecting the same were also studied.

INCLUSION CRITERIA: Children in the age group of one month to five years with clinical features of severe pneumonia as per WHO recommendations for the control of ARI were included.

EXCLUSION CRITERIA: Children with congenital anomalies of heart and lungs, anatomical defects like cleft lip and cleft palate, immunocompromised states like human immunodeficiency virus infection (HIV) and infants less than one month of age were excluded from the study.

A detailed history of the relevant symptoms such as fever, cough, rapid breathing, refusal of feeds, wheezing etc. was taken.

TACHYPNOEA: Based on WHO ARI criteria, children were considered tachypnoeic if Respiratory rate $(\mathrm{RR})$ :

- $\mathrm{RR}>60$ in $<2$ months.

- $\mathrm{RR}>50$ in 2 months $-1 \mathrm{yr}$.

- $\mathrm{RR}>40$ in $1 \mathrm{yr}-5 \mathrm{yrs}$.

A detailed examination of each child including anthropometry was carried out. During the general physical examination, emphasis was laid on assessing general condition of the child, respiratory rate (counted over one minute), presence of fever and other signs such as cyanosis and pallor, detailed systemic examination of the respiratory, cardiovascular and central nervous system as done. Any associated illness such as septicemia, meningitis and congestive cardiac failure if present was noted. Other pertinent information such as immunization status (Immunized, partially immunized or unimmunized), feeding practices and degree of malnutrition (IAP classification) were also recorded.

\section{Following Investigations were carried out:}

- $\quad$ Routine Investigations like Hb, TC, DC, ESR was done in all cases.

- Chest X-ray was taken in all patients.

- Blood culture was done in relevant cases.

Based on radiological findings, children were divided into Bacterial (consolidation, alveolar infiltrates) and Viral (interstitial infiltrates, hyper aeration) pneumonia, repeat radiological study was done to look for radiological clearance after treatment. 


\section{ORIGINAL ARTICLE}

All patients received antibiotics. Supportive care (IV fluids, Oxygen, nebulisation etc) was given as and when required. Antibiotics that were used:

1. First line antibiotics: Crystalline Penicillin with Amikacin.

2. Second line antibiotics: Cefotaxime/Ceftriaxone with Amikacin.

3. Others: Cloxacillin.

Majority of patients (Except pneumonia with complications) received first line antibiotics. Those children who failed to respond to $1^{\text {st }}$ line antibiotics within 48 hours received second line antibiotics. Cloxacillin was considered in cases of empyema/massive consolidation. Closed tube drainage was considered in cases of empyema. All children were evaluated during their hospital stay and the response to treatment was noted

OBSERVATION AND RESULTS: In the present study, 200 cases of severe pneumonia were studied.

\begin{tabular}{|c|c|c|}
\hline Age groups & Number of cases & Percentage \\
\hline $1 m-6 m$ & 67 & 33.5 \\
\hline $7 m-12 m$ & 52 & 26 \\
\hline $13 m-60 m$ & 81 & 40.5 \\
\hline
\end{tabular}

Table 1: Distribution of cases according to age

\begin{tabular}{|c|c|c|}
\hline Sex & Number of cases & Percentage \\
\hline Male & 130 & 65 \\
\hline Females & 70 & 35 \\
\hline
\end{tabular}

Table 2: Distribution of cases according to sex

\begin{tabular}{|c|c|c|}
\hline Symptoms & Number & Percentage \\
\hline Cough & 199 & 99.5 \\
\hline Fever & 184 & 92 \\
\hline Hurried breathing & 200 & 100 \\
\hline Refusal of feeds & 80 & 40 \\
\hline Wheeze & 50 & 25 \\
\hline Convulsions & 15 & 7.5 \\
\hline Cyanosis & 8 & 4 \\
\hline
\end{tabular}

Table 3: Showing various symptoms

\begin{tabular}{|c|c|c|}
\hline Signs & No. & Percentage \\
\hline Chest retractions & 200 & 100 \\
\hline Crepitations & 171 & 85.5 \\
\hline Rhonchi & 74 & 37 \\
\hline Abnormal breath sounds & 21 & 10.5 \\
\hline \multicolumn{3}{|c|}{ Table 4: Showing various signs } \\
\hline
\end{tabular}




\section{ORIGINAL ARTICLE}

\begin{tabular}{|c|c|c|c|}
\hline \multirow{2}{*}{$1 \mathrm{~m}-12 \mathrm{~m}$} & $>80$ & $60-80$ & $<60$ \\
\cline { 2 - 4 } & 19 & 67 & 33 \\
\hline \multirow{2}{*}{$13 m-60 m$} & $>60$ & $50-60$ & $40-50$ \\
\cline { 2 - 4 } & 34 & 11 & 36 \\
\hline
\end{tabular}

Table 5: Respiratory rate at admission

\begin{tabular}{|c|c|c|}
\hline Illness & Number & Percentage \\
\hline Septicemia & 11 & 5.5 \\
\hline Meningitis & 5 & 2.5 \\
\hline Diarrhea & 24 & 12 \\
\hline CCF & 6 & 3 \\
\hline
\end{tabular}

Table 6: Associated illness

\begin{tabular}{|c|c|c|}
\hline Season & Severe pneumonia 115 & Very severe pneumonia 85 \\
\hline Summer (Feb to May) & 54 & 28 \\
\hline Rainy (June to Sept) & 19 & 21 \\
\hline Winter (Oct. to Jan) & 42 & 36 \\
\hline \multicolumn{2}{|r|}{ Table 7: Showing seasonal distribution of cases } \\
\hline
\end{tabular}

\begin{tabular}{|c|c|c|}
\hline Classification & No. & Percentage \\
\hline Severe Pneumonia & 122 & 61 \\
\hline Very severe Pneumonia & 78 & 39 \\
\hline
\end{tabular}

Table 8: Classification according to WHO ARI programme

\begin{tabular}{|c|c|c|}
\hline Diagnosis & No. & Percentage \\
\hline Bronchopneumonia & 166 & 83 \\
\hline Lobar Pneumonia & 12 & 6 \\
\hline Pneumonia and its complications & 16 & 8 \\
\hline Post Measles Bronchopneumonia & 6 & 3 \\
\hline \multicolumn{2}{|c|}{ Table 9: Clinical Diagnosis } \\
\hline
\end{tabular}

\begin{tabular}{|c|c|c|}
\hline Diagnosis & No. & Percentage \\
\hline Bacterial Pneumonia & (128) & $(64)$ \\
\hline A] Lobar consolidation & 63 & 31.5 \\
\hline B] Alveolar Infiltrates & 48 & 24 \\
\hline C] Complications & 17 & 8.5 \\
\hline Viral Pneumonia & 35 & 17.5 \\
\hline Normal & 37 & 18.5 \\
\hline \multicolumn{3}{|c|}{ Table 10: Radiological findings } \\
\hline
\end{tabular}




\section{ORIGINAL ARTICLE}

\begin{tabular}{|c|c|}
\hline & Number \\
\hline Culture sent & 64 \\
\hline Not sent & 136 \\
\hline No growth & 30 \\
\hline Positive & $5(7.8 \%)$ \\
\hline Contaminated & 29 \\
\hline
\end{tabular}

Table 11: Culture

Management: In the present study, blood culture was positive in only 7. 8\% of cases. S. pneumonia was the most common organism isolated ( 3 cases) followed by S. aureus ( 2 cases).

In the present study, all patients received antibiotics and supportive care.

\begin{tabular}{|c|c|c|}
\hline Antibiotics & No. & Percentage \\
\hline First line & 166 & 83 \\
\hline Second line & 28 & 14 \\
\hline${\text { Changed from } 1^{\text {st }} \text { to } 2^{\text {nd }}}^{\text {Chatiotics added }}$ & 20 & 10 \\
\hline Antibiotis & 18 & 9 \\
\hline Oral antibiotics at discharge & 56 & 28 \\
\hline \multicolumn{2}{|c|}{ Table 12: Antibiotics }
\end{tabular}

\begin{tabular}{|c|c|c|}
\hline Immunization & No. & Percentage \\
\hline Immunized & 106 & 53 \\
\hline Partially immunized & 64 & 32 \\
\hline Unimmunized & 30 & 15 \\
\hline
\end{tabular}

Table 13: Showing Immunization status

\begin{tabular}{|c|c|c|}
\hline Feeding & No. & Percentage \\
\hline Breast fed & 155 & 77.5 \\
\hline Bottle fed & 45 & 22.5 \\
\hline \multicolumn{3}{|c|}{ Table 14: Feeding Practices } \\
\hline
\end{tabular}

\begin{tabular}{|c|c|c|}
\hline IAP & No. & Percentage \\
\hline Normal & 96 & 48 \\
\hline Grade I & 42 & 21 \\
\hline Grade II & 32 & 16 \\
\hline Grade III & 20 & 10 \\
\hline Grade IV & 10 & 5 \\
\hline
\end{tabular}

Table 15: Protein energy malnutrition 


\section{ORIGINAL ARTICLE}

DISCUSSION: Pneumonia continues to pose a threat to healthy children in developed and developing countries despite improvements in socioeconomic status, immunization and early diagnosis and treatment. Universality, vulnerability and frequency of occurrence of ALRTI in children are well recognized all over the world.

AGE DISTRIBUTION: Age is an important predictor of morbidity and mortality in pediatric pneumonias.

In the present study, conducted between the age group of one month to five years, majority $(59.5 \%)$ were less than one year. This was in comparison with studies done by Reddaiah VP et al ${ }^{4}$ $(63.2 \%)$ and Sehgal $V$ et $a^{5}$ (52.2\%).

SEX DISTRIBUTION: In our study it was observed that males (65\%) out weighed females (35\%). Male: female ratio was 1.9 .

This was in comparison with studies done by Sehgal V et $\mathrm{al}^{5}$ (58.2\%) and Drummond P et al. 6 (58\%). Symptomatology:

The WHO protocol puts forward two signs as the "entry criteria" or basis for examining a child bellow five years of age for possible pneumonia: cough or difficult breathing.

\begin{tabular}{|c|c|c|c|}
\hline Symptoms & Kabra SK et al $^{\mathbf{1 2}}$ & Kumar N et a $^{\mathbf{4}}$ & Present study \\
\hline Fever & $82 \%$ & $88 \%$ & $92 \%$ \\
\hline Cough & $98 \%$ & $100 \%$ & $99.5 \%$ \\
\hline Hurried Breathing & $90 \%$ & $100 \%$ & $100 \%$ \\
\hline Refusal of feeds & $42 \%$ & $22 \%$ & $40 \%$ \\
\hline \multicolumn{4}{|c|}{ Table 16: Symptomatology } \\
\hline
\end{tabular}

The incidence of presenting symptoms in our study is comparable with studies conducted by Kabra SK et $\mathrm{al}^{7}$ and Kumar $\mathrm{N}$ et al.

SIGNS: In our study, tachypneoa (100\%) and chest retractions (100\%) were the important signs for making a clinical diagnosis of pneumonia. Crepitations (85.5\%), rhonchi (37\%) and abnormal breath sounds (10.5\%) were the other associated signs.

Gupta D et al,8 Margolis P et al,46 Palafox M et al, ${ }^{9}$ and Gadomski AM et al have observed that tachypnoea and chest retractions were highly specific signs in detecting pneumonia.

Reddaiah VP et al, have reported that crepitations were found in $76 \%$ and rhonchi in $23.2 \%$ of patients with pneumonia.

ASSOCIATED ILLNESS: In our study, pneumonia was associated with diarrhea in $12 \%$ (24 cases), congestive cardiac failure in 3\% (6 cases), and septicemia in 5.5\%. This was in comparison with studies done by Deivanayagam $\mathrm{N}$ et $\mathrm{al},{ }^{10}$ and Sehgal $\mathrm{V}$ et al

CLINICAL DIAGNOSIS: In our study Bronchopneumonia was the most common diagnosis made at admission (83\%), Lobar pneumonia in 6\%, pneumonia with complications in $8 \%$ and post measles Bronchopneumonia in 3\% of cases. Complications of pneumonia include empyema (3.3\%), pleural effusion (1.2\%), collapse (1.2\%) and pneumothorax $(1.2 \%)$. 


\section{ORIGINAL ARTICLE}

In a study conducted by Reddaiah V.P et al, Bronchopneumonia was diagnosed in 64\%, Lobar pneumonia in $6.4 \%$ and post measles bronchopneumonia in $4.0 \%$ of cases.

RADIOLOGICAL FINDINGS: Although clinical symptoms and signs are helpful indicators of the presence of disease as well as etiology, radiographic investigation is often used to confirm a clinical diagnosis and to help sort out whether or not antibiotics or more extensive work up is necessary.

In our study Chest X-ray showed radiological changes consistent with pneumonia in $81.5 \%$ of cases. Evidence of bacterial infection was found in $64 \%$ and viral in $17.5 \%$ of cases.

In a study conducted by Virkki $\mathrm{R}$ et al, ${ }^{11}$ it was found that radiological changes were seen in $85 \%$, with evidence of bacterial infection in $64 \%$ and viral in $36 \%$ of cases. Macintyre C.R. et al have also reported radiological confirmation in $85 \%$ of cases of pneumonia.

In our study, follow up radiographs were taken in $60 \%$ of cases; $80 \%$ showed complete resolution after treatment and $20 \%$ partial resolution.

Heaton $\mathrm{P}$ et al,12 in their study on utility of chest radiography in the follow up of pneumonia, has found that $90.2 \%$ had normal chest radiographs after treatment. They also concluded that in cases of uncomplicated pneumonias, follow up chest radiography is not indicated if symptoms and signs are absent.

Blood Culture: In recent years, the best information on the bacterial etiology of pneumonia in young children has been obtained through blood culture, despite the fact that the sensitivity of this method is somewhat lower.

In our study, blood culture was positive in 5 cases (7.8\%). S pneumonia was the most common organism isolated (4cases) followed by S.aureus.

Kabra SK et $\mathrm{al}^{13}$ and Bahl $\mathrm{R}$ et la have reported positive blood culture in $16 \%$ and $11 \%$ of patients respectively. The yield of blood cultures varies from $5-15 \%$ for bacterial pathogens and cannot be relied upon. Because of very low positivity of blood culture, we could not correlate our clinical findings with etiological diagnosis.

Management: Management of pneumonia includes supportive care and antibiotics. Because definitive information about causative pathogens is seldom available, treatment of pneumonia is most often empiric.

In our study all patients received antibiotics. Majority (83\%) responded to first line antibiotics (crystalline penicillin and amicacin). 14\% did not respond to first line, hence received second line antibiotics. 9\% (18 cases) received cloxacillin in addition of first line antibiotics.

Duke $\mathrm{T}$ et $\mathrm{al}^{14}$ have established that combination of crystalline penicillin with amikacin would be better as first line treatment in children with sever pneumonia in less developed countries.

WHO has recommended that crystalline penicillin is one of the standard antimicrobial for the treatment of severe pneumonia.

In our study, antibiotics were changed in $10 \%$ of cases. Similar observation was made by Duke T et al where in antibiotics were changed in $11 \%$ of patients.

SUMMARY: This hospital based prospective study of severe pneumonia included 200 children who were admitted to pediatric wards with symptoms and signs suggestive of severe pneumonia according to the WHO ARI control programme. 


\section{ORIGINAL ARTICLE}

The most affected children belonged to the age group of one month to one year (59.5\%). Males out weighed females with male to female ratio of 1.9 .

Hurried breathing (100\%), cough (99.5\%) and fever (92\%) were the most common symptoms. Refusal of feeds was present in $40 \%$ of cases. Tachypnoea (100\%), chest retractions (100\%) and crepitations (85.5\%) were the most common signs.

Diarrhea (12\%), septicemia (5.5\%) and meningitis (2.5\%) were the associated illness.

Bronchopneumonia (83\%) was the most common clinical diagnosis made at admission. A diagnosis of lobar pneumonia was made in $6 \%$ and pneumonia with its complications in $8 \%$ of cases. According to WHO ARI control programme, 61\% had severe pneumonia and $39 \%$ had very severe pneumonia.

$80 \%$ of cases showed complete radiological resolution after treatment.

In this study, $53 \%$ were immunized to date and $15 \%$ did not receive any vaccine. $77.5 \%$ were breast-fed and $22.5 \%$ were given bottle feeds.

$52 \%$ were malnourished and 50\% were anemic. 37\% had Grade I and II PEM and 15\% had Grade III and IV PEM.

Blood culture was positive in $7.8 \%$ of cases. S. pneumonia was the commonest organism isolated followed by S. aureus.

Majority (83\%) responded to crystalline and amikacin. 14\% of cases did not respond to first line, hence received second line antibiotics. Cloxacillin was added in $9 \%$ of cases

\section{CONCLUSION:}

- ARI, especially severe pneumonia is one of the major causes of morbidity and mortality in children. Bronchopneumonia is the predominant form of presentation in infants and preschool children.

- Among the risk factors studied, inappropriate immunization for age, anemia, PEM grade III and IV were significant risk factors in severe pneumonia.

- Symptoms and signs mentioned in the WHO ARI control programme were very sensitive and can be applied to hospitalized children.

- Routine hematological investigations and blood culture will not give much information regarding severity or etiology of illness.

- Chest X-ray is a valuable aid in the diagnosis of pneumonia in children. Follow up chest roentgenogram is vital for evaluating the response to treatment in pneumonia.

- Crystalline Penicillin and amikacin are still the antibiotics of choice in pneumonia. Indiscriminate use of higher antibiotics in not justified, in view of emergence of drug resistant organisms.

\section{BIBLIOGRAPHY:}

1. World Health Organization programme for the control of acute respiratory infections. Acute Respiratory Infections in children: Case Management in small hospitals in developing countries. A manual for doctors and other senior health workers, Geneva, WHO, 1990. WHO. ARI. 90.5.

2. World Health Organization programme for the control of acute respiratory infections. Technical bases for the WHO recommendations on management of pneumonia in children at first level health facilities. Geneva, WHO, 1991; WHO.ARI.91.20. 


\section{ORIGINAL ARTICLE}

3. Jadavji T, Law B, Lebel MH, Kennedy WA, Gold R, Wang EEL. A practical guide for the diagnosis and treatment of pediatric pneumonia. Can Med Assoc J 4.Reddaiah VP and Kapoor SK. Acute respiratory infections in under fives: Experience at comprehensive rural health services project hospital, Ballabgarh. Indian J Community Med 1995; 20:1-4.

4. Sehgal V, Sethi GR, Sachdev HPS, Satyanarayana V. Predictors of mortality in subjects hospitalized with acute lower respiratory tract infection. Indian Pediatr 1997; 34:213-19.

5. Drummond P, Clark J, Wheeler J, Galloway A, Freeman R, Cant A. Community acquired pneumonia - a prospective UK study. Arch Dis Child 2002; 83: 408-121997; 156(Suppl): S703-11.

6. Kabra SK, Broor S, Lodha R, Maitreyi RS, Ghosh M, Pandey RM, et al. Can we identify acute severe viral lower respiratory tract infection clinically? Indian Pediatr 2004; 41:245-49.

7. Gupta D, Mishra S, Chaturvedi P. Fast breathing in the diagnosis of pneumonia - a reassessment. J Trop Pediatr 1996; 42:196-99.

8. Palafox M, Gulscafre H, Reyes H, Mufioz O, Martinez H. Diagnostic value of tachypnoea in pneumonia defined radiologically. Arch Dis Child 2000; 82:41-45.

9. Deivanayagam N, Nedunchelian K, Ramaswamy S, Sudhandirakannan, Ratnam SR. Risk factors for fatal pneumonia: A case control study. Indian Pediatr 1992; 29: 1529-32.Kabra SK, Verma IC. Acute lower respiratory tract infection: The forgotten pandemic. Indian J Pediatr 1999; 66: 873-75.

10. Virkki R, Juven T, Rikalainen H, Svedstrom E, Mertsola J, Ruuskanen O. Differentiation of bacterial and viral pneumonia in children. Thorax 2002; 57: 438-41.

11. Heaton P, Arthur K. The utility of chest radiography in the follow-up of pneumonia. N Z Med J 1998; 111:315-17.

12. Kabra SK, Lodha R, Broor S, Chaudhary R, Ghosh M and Maitreyi RS. Etiology of Acute Lower Respiratory Tract Infection. Indian J Pediatr 2003; 70:33-36.

13. Duke T, Poka H, Dale F, Michael A, Mgone J, Wal T. Chloramphenicol versus benzyl penicillin and gentamincin for the treatment of severe pneumonia in children in Papua New Guinea: a randomized trial. The Lancet 2002; 359: 474-80. 


\section{ORIGINAL ARTICLE}

\section{AUTHORS: \\ 1. Y. Siva Rama Krishna \\ 2. K. Ramireddy \\ 3. S. Aparna \\ 4. G. Anusha \\ 5. S. Mounika \\ 6. K. Sandeep}

\section{PARTICULARS OF CONTRIBUTORS:}

1. Assistant Professor, Department of Pediatrics, Guntur Medical College Guntur.

2. Assistant Professor, Department of Pediatrics, Guntur Medical College Guntur.

3. Pharm. D Student, Chalapathi Institute of Pharmaceutical Sciences, Guntur.

\section{FINANCIAL OR OTHER}

COMPETING INTERESTS: None
4. Pharm. D Student, Chalapathi Institute of Pharmaceutical Sciences, Guntur.

5. Pharm. D Student, Chalapathi Institute of Pharmaceutical Sciences, Guntur.

6. Pharm. D Student, Chalapathi Institute of Pharmaceutical Sciences, Guntur.

\section{NAME ADDRESS EMAIL ID OF THE \\ CORRESPONDING AUTHOR:}

Dr. Y. Siva Rama Krishna,

Flat No. 201,

Sri Sai Krishna Residency,

1/3 Chandramouli Nagar,

Guntur-522007.

E-mail: ysivasri@gmail.com

Date of Submission: 13/03/2015.

Date of Peer Review: 14/03/2015.

Date of Acceptance: 23/03/2015.

Date of Publishing: 04/04/2015. 